\title{
Lumbosacral lipomas: critical survey of 26 cases submitted to laminectomy
}

\author{
L. P. LASSMAN AND C. C. MICHAEL JAMES \\ From the Regional Neurological Centre, Newcastle General Hospital, \\ and the University of Newcastle, Newcastle upon Tyne
}

Lipomas in the lumbosacral region produce their tragedies because their pathological anatomy is not sufficiently widely appreciated nor are their secondary effects recognized. These fatty swellings are apparently benign but they commonly have a continuation passing deeply to connect with the spinal cord, filum terminale, or cauda equina which is liable to interfere with conduction in these structures or cause ischaemia by traction during the course of growth during childhood or by pressure owing to increase in fat content within the theca. The resulting deficit involves sensory and motor loss in the lower limbs, bladder, and bowel of varying degree from minor muscular paresis and foot deformity to incontinence, paraplegia, or trophic ulceration leading to loss of part of a limb. Deficit may be present at birth but it may not occur until middle age and then usually in the form of bladder incontinence.

We have encountered 26 cases of lumbosacral lipoma in the first 100 cases of spina bifida occulta which we have operated on. This communication is based on our experience and details the findings in this series of cases with the purpose of indicating the need for investigation and for surgical removal of the lipoma, including exploration within the theca. Superficial removal for cosmetic reasons is not sufficient because subsequent exploration occasioned by the later development of neurological deficit is made both difficult and dangerous.

In this personal series of 26 cases, four were women and 22 were children aged 8 months to 12 years; only four were male. Some of these have been mentioned in our earlier publications (James and Lassman, 1958, 1960, 1962a, 1962b, 1963, 1964).

\section{CLINICAL SYNDROME}

In all cases there is a superficial fatty tumour (Fig. 1) over the lumbosacral region in or near the midline which may be very large and rounded measuring between 20 and $30 \mathrm{~cm}$. at the base transversely and rising as much as $15 \mathrm{~cm}$. above the surface of the $\frac{\bar{D}}{\vec{D}}$

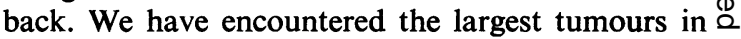
our younger children whilst the smaller, being less $\nRightarrow$ obvious, are seen in older patients, but the excess $\overrightarrow{0}$ fat of these smaller swellings is distinguishable from normal body fat even in obese adults. The very size $\vec{\omega}$ of the tumour relative to the body of a child causes parents to seek advice so that a number of cases are seen in surgical clinics solely for cosmetic reasons. Seven of our patients were otherwise normal whilst 0 the remaining 19 had associated clinical abnormales ties which had been observed to become mor $\vec{A}$ severe before they were referred to us. Four patient had previously had the lipoma removed superficial $\stackrel{2}{-}$ without exploration to find a deep connexion. The $\vec{D}$ skin covering is healthy although excessive hair, $\frac{a}{2}$ naevus, dimples, or a discharging sinus may present as well.

The associated clinical abnormalities mainfy. affect one lower limb but occasionally both. They are the result of a progressive myelopathy or neuropathy producing muscle weakness, paresis or spasticity, foot deformity, commonly cavovarus but occasionally valgus, and often with sensory changes $\stackrel{\mathbb{Q}}{\perp}$

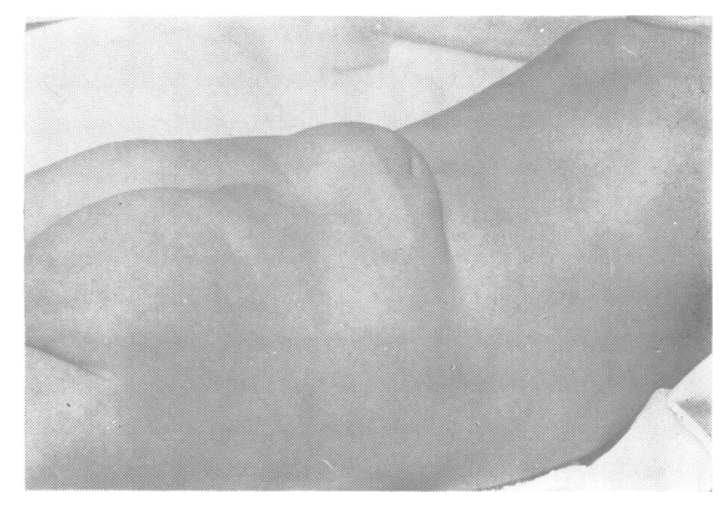

FIG. 1. Superficial lipoma. 
and trophic ulceration. Abnormal bladder function also occurs.

It is convenient to divide the 19 cases with clinical abnormality into two groups, group 1 consisting of 15 children aged 8 months to 12 years, and group 2 consisting of four adults aged 17 years to 29 years at the time of laminectomy.

GROUP 1: 15 CHILDREN One child had a discharging sinus associated with a lipoma but was otherwise clinically normal; another had a similar sinus but was incontinent also. Five were affected in both lower limbs, two having spasticity, two bilateral cavovarus and unilateral limb weakness, and one with relapsing club feet and bladder incontinence.

Eight were affected unilaterally, three being incontinent as well as having whole limb weakness and foot deformity. The other five had similar foot deformities associated with paralysis of peronei or of foot invertors or of weakness in these muscles; one had a spastic equinus. Most of these cases had sensory loss of some degree including loss of vibration sense and diminished postural sensibility, areas of anaesthesia and of analgesia, and one had trophic ulceration of the toes.

GROUP 2: FOUR ADULTS Two of these, aged 17 and 23 years, had progressive foot deformity and trophic ulceration starting many years before and had been progressing in a similar pattern to the less severely affected children in group 1 . Two, aged 25 and 29 years, had no lower limb abnormality but had bladder incontinence, one with constant dribbling and the other retention with overflow. Both these patients had been normal until the age of 18 years when they had started developing symptoms of bladder weakness and recurrent infection. This pattern of late onset contrasts with our incontinent cases in group 1 who seem to have had bladder weakness of varying degree from birth or shortly after.

\section{INVESTIGATIONS}

RADIOGRAPHY Although Brickner (1918) has stated that some cases of lipoma are not associated with spina bifida, every one in our own series showed laminal defects on radiography. These defects were in the lumbar and sacral regions with widening of the interpedicular distances in the region of the intrathecal anomaly. Some degree of dysgenesis of the sacrum existed in five patients, one of whom had sacral somatoschisis; none had evidence of bladder weakness in contrast to the cases reported by Williams and Nixon (1957).

MYELOGRAPHY Myelography is essential to final diagnosis. Dr. G. L. Gryspeerdt has been responsible for the myelographic examination of our patients and has developed an important technique for demonstrating the level of the conus medullaris (1963). Myodil is used and is introduced by the cisternal route with the patient under general anaesthesia. The anaesthetic technique used for our cases at myelography has been reported by Whitby (1961).

Various abnormalities may be demonstrated, such as a filling defect due to an intraspinal lipoma, diastematomyelia, or only a low-placed conus medullaris (at or caudal to Lv3 body). The latter may be the only myelographic evidence of an intrathecal extension from the subcutaneous lipoma. An unsuspected meningocoele within the lipoma may also be shown. Every case in this series showed some abnormality at myelography.

\section{TREATMENT}

Treatment consists of laminectomy, exposure, and opening of the dura mater and exploration of the spinal cord and cauda equina. The mass of fat is exposed through a longitudinal elliptical incision and is dissected from the skin until its peripheral margins can be defined and separated from the lumbodorsal fascia; in this process the deep midline extension or stalk of the lipoma will become apparent in most cases. The fascia is incised longitudinally and the muscle retracted to bare the laminae (Fig. 2). Bassett (1950) advocates a transverse incision but, since it is necessary to remove adjacent laminae to expose the dura mater satisfactorily, we prefer a longitudinal approach because it is more easily extended to give wider access to the dura should the

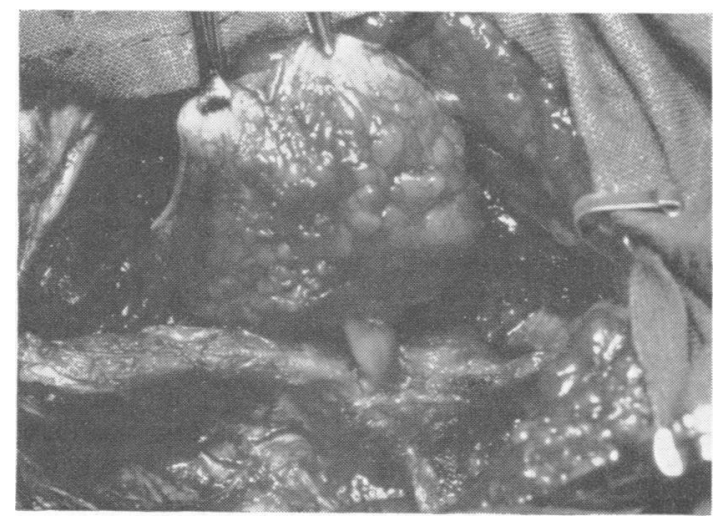

FIG. 2. Lipoma showing the stalk passing through the gap in the spinous processes. The muscles have been dissected from the laminae. 
need arise; the scar is just as satisfactory. If the stalk of the lipoma has been localized it should be kept intact and its internal continuation traced intrathecally by opening the dura above and below it. If the subcutaneous fatty mass is bulky most of it may be removed at this stage. The lipoma with its stalk is then turned upwards towards the patient's head, and in most cases the nerve roots of the cauda equina will fall away from it to allow identification of its attachment to the intrathecal structures and for its excision as near to these structures as possible. By this manoeuvre the fat can usually be completely removed in children without difficulty, although the experience of Dubowitz, Lorber, and Zachary (1965) differed from ours in this respect. However, removal of the fat in adults is particularly difficult because it is diffuse and it may be possible only to decompress the nervous tissue. In some cases the stalk is attached to the conus either directly or as part of the filum terminale and can easily be cut off, but where it attaches to the cauda equina, sharp dissection is needed to free it from the nerve roots. Even if no stalk from the lipoma is found, the dura must be opened to make sure that any internal continuation is removed and that there is no other anomalous tissue likely to tether or compress the spinal cord. The dura mater and other structures are closed in the usual manner.

\section{ABNORMALITIES FOUND AT OPERATION}

As Brickner (1918), Ingraham and Swan (1943), and Ingraham and Lowrey (1943) have already pointed out, these congenital lipomas differ from the other varieties described at other sites because they are not encapsulated, are finely lobulated and much like subcutaneous fat. Each of our cases was diagnosed on clinical examination as having a subcutaneous lipomatous tumour on the back which was not cystic and did not transilluminate. Associated with evidence of laminal defect seen on plain radiographs (one lipoma was shown to contain anomalous bone), they were all regarded as cases of spina bifida occulta. More accurate distinction from spina bifida cystica was not obtainable until myelography or surgical exploration could make it clear whether the meninges herniated out of the vertebral canal or not, although we have found that lipomas which extend away from the midline towards one side are more likely to contain a meningocoele or a meningomyelocoele. In this series there is one case which was almost one of meningomyelocoele, the spinal cord being kinked dorsally by direct connexion with the lipoma immediately cranial to the conus but without actual extrusion from the vertebral canal; the myelogram indicated only a wide dorsal filling defect within the theca. Another case, which we have retained in this series, had a very small meningocoele sac, demonstrated by myelography, which was connected to the vertebral canal by a very fine channel. The lipoma was large, concealing the meningocoele within it and was directly adherent to the conus medullaris.

Of our 26 cases, 18 had an easily traceable connexion between the subcutaneous lipoma and the nervous tissues within the theca whilst in eight no such connexion was found (Table I). Five of the seven cases of diastematomyelia in this series were included in our survey of that abnormality (James and Lassman, 1964).

TABLE I

RELATIONSHIP OF THE SUBCUTANEOUS LIPOMAS WITH INTRATHECAL STRUCTURES

Preoperative State

Connexion

Direct Connexion Traced (18 cases)

Normal

Discharging sinus

To spinal cord

Discharging sinus and

incontinence

Progressive neuropathy

Total

Normal

Incontinence

Total

Normal

$\begin{aligned} 3 & \text { To spinal cord } \\ 1 & \\ 1 & \\ 9 & \\ 14 & \\ 1 & \text { To filum terminale } \\ 2 & \\ 3 & \\ 1 & \text { To cauda equina }\end{aligned}$

No Traceable Connexion (8 cases)

Normal

Progressive neuropathy

Total

Normal

Progressive neuropathy

Total

Diastematomyelia

Tight filum terminale

CASES WITH TRACEABLE CONNEXION In all these cases the connexion between the lipoma and the nervous tissue was easily identifiable by the increasing fibrosis encountered with deep dissection. Microscopy confirmed the macroscopic appearances, the extradural portion was principally fatty superficially, but more deeply the tissue became increasingly densely fibrous with some fat interspersed. The connexion reached the dura through a defect in a neural arch and its diameter at this point varied between 8.0 and $0.5 \mathrm{~cm}$. in different cases. Within the dura the continuation was usually dense fibrous tissue, only a few millimetres in diameter, although in a few of much greater diameter there was a considerable admixture of fat.

Three cases had had the lipoma removed superficially some years previously; one of them continued to have a discharging sinus. In two the remains were easily identifiable but the added fibrosis made exploration very difficult; in the third case, although the continuation could be identified, the previous operation had been much more thorough and must have extended very deeply because the resulting 
adhesions continued through the dura to the underlying spinal cord and the operation had to be ended without even an attempt at releasing the tension. This is the only case in this series which has been made worse by our operation; the child was previously continent, but lost her bladder control afterwards.

One infant had a sinus opening on the surface of the lipoma which continued into a sausage-shaped intrathecal lipoma overlying the filum terminale and cauda equina and attached to the conus medullaris. The sinus was lined by alimentary mucus-secreting epithelium, and the intrathecal lipoma near its attachment to the conus medullaris contained glial tissue, ependymal canals, and motor type neurones.

In 14 of these 18 cases with a direct traceable connexion from the subcutaneous lipoma, the connexion was with the spinal cord itself, either to the conus medullaris or immediately cranial to it. In one the connexion joined the spinal cord at the caudal bifurcation of diastematomyelia without a septum and in another the connexion in its intrathecal part included a discrete lipoma which contained nerve strands and small concentric nodules of fibrous tissue, possibly extensions of arachnoid. In 11 of these cases, the filum terminale was a welldefined and separate structure, but in three the filum terminale could not be identified and it was possibly a part of the lipoma connexion.

In three further cases the lipoma connexion was clearly continued as the filum terminale (Fig. 3 and 4) and in one of them the superficial origin of the connexion was to a dermal dimple which continued as the filum terminale and joined the conus through a small intrathecal lipoma; when the filum was cut from the conus, the latter was seen to move cranially. In a second case, an adult, besides the connexion to the filum there was extensive fibrous adhesion of the spinal cord to the dura cranial to the area of the subcutaneous lipoma.

In the last of these 18 cases, the lipoma connexion was by adhesions to the left cauda equina which was held dorsally in part of its course as though there had been an attempt at meningocoele formation.

The group as a whole provides an illustration of the close affinity of the two principal forms of spina bifida, aperta and occulta, an aspect which we have discussed elsewhere (Lassman and James, 1964).

CASES WITH NO TRACEABLE CONNEXION Six cases had diastematomyelia. Three of them had no septum; the usual bands which we have described (James and Lassman, 1964) originated extradurally in defective laminae and so could possibly have been joined to the subcutaneous lipoma, but no distinct connexion was found. Three had bone septa and two of them

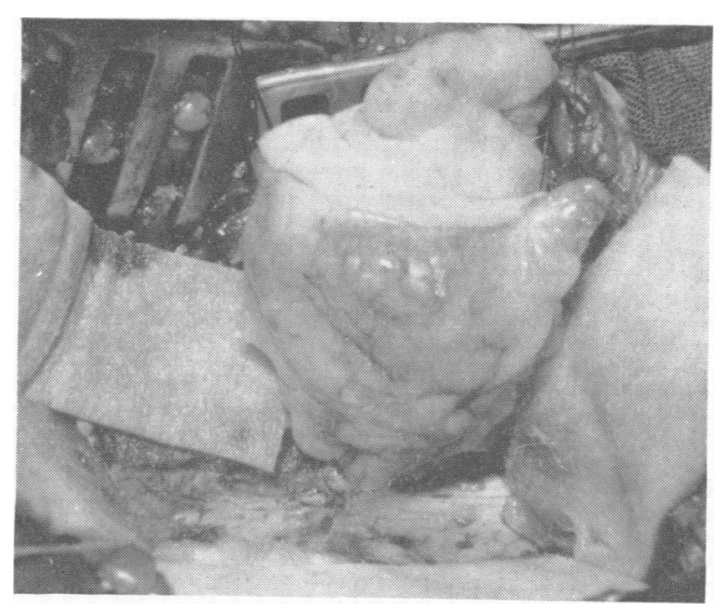

FIG. 3. Lipoma with stalk which is seen to be passing through the dura mater which has been exposed by removal of the laminae (same case as Fig. 4).

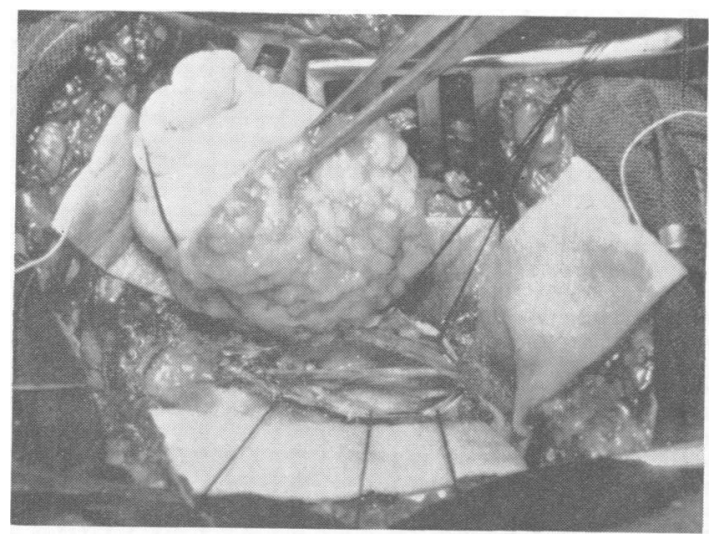

FIG. 4. The dura mater has been opened and the stalk of the lipoma drawn to the left is seen to be continuous with the filum terminale (same case as Fig. 3).

are worthy of further comment. In one the intrathecal bands were unusual since they were recurrent and had no extradural continuation except adhesion to the internal surface of the dura; they appeared to be nerve fibres arising from one of the two spinal cords and returning near to their point of origin. The other case had two areas of diastematomyelia, the first at least $1 \mathrm{~cm}$. long lying deep to Lv4 neural arch and without a septum, the second area $2 \mathrm{~cm}$. long with a bone septum was $1.5 \mathrm{~cm}$. cranial to the first, and a further $2.0 \mathrm{~cm}$. cranial again was an area of hydromyelia which must have been a dilatation of the central canal of the spinal cord which 
Lichtenstein (1940) described as occurring in diastematomyelia.

The remaining two cases in this group had a tight filum terminale which was holding the spinal cord and cauda equina abnormally dorsally: in one of them the subcutaneous lipoma had been previously excised superficially as a possible teratoma because it had contained a discharging sinus in the centre of a naevoid area; the filum terminale and cauda equina were adherent to the dura dorsally near the end of the dural sac. In both these cases severance of the filum left a substantial gap between the cut ends and the conus and cauda equina fell into the normal position. Unlike the cases of tight filum terminale reported by Schlegel (1964) neither of our cases had bilateral pes cavus.

\section{RESULTS}

The purpose of the operation is to prevent further deterioration since it is not known with certainty beforehand exactly what abnormality will be encountered. If such precise information were available, a prognosis would be relatively simple and operation could then be reserved for only those cases which could be expected to deteriorate if left untreated. Table II shows the results so far in our 26 cases and the length of follow-up. Of the 18 cases with neuropathy before operation, one is worse as a result of the operation, one deteriorated five years later, seven are unchanged, and nine are improved.

Eight children were seen because of the lumbosacral lipoma and none then had any other physical abnormality but by the time that she was admitted for operation one of them aged less than 12 months showed evidence of spasticity in the lower limbs; two years later the spasticity was still present but of less degree than would be anticipated from her preoperative state. One child, still normal one year after operation, was killed in a road accident and the remaining six continue to be normal (Table II).

TABLE II

\begin{tabular}{|c|c|c|c|}
\hline \multicolumn{4}{|c|}{ RESULTS AND LENGTH OF FOLLOW-UP } \\
\hline $\begin{array}{l}\text { Clinical State before } \\
\text { Operation }\end{array}$ & & Present State & $\begin{array}{l}\text { Follow-up } \\
(y r .)\end{array}$ \\
\hline $\begin{array}{l}\text { Uncomplicated lipoma } \\
\text { Discharging sinus } \\
\text { Discharging sinus with } \\
\text { incontinence } \\
\text { Incontinence } \\
\text { Progressive neuropathy }\end{array}$ & $\begin{array}{r}7 \\
1 \\
1 \\
2 \\
15\end{array}$ & $\begin{array}{l}\text { All normal } \\
\text { Normal } \\
\text { Unchanged } \\
\text { Improved } \\
\text { One worse as a result of } \\
\text { operation } \\
\text { One worse } 4 \frac{1}{2} \text { years later } \\
\text { Six unchanged } \\
\text { Seven improved }\end{array}$ & $\begin{array}{l}5 \\
3 \\
5 \\
2-5 \\
1-5\end{array}$ \\
\hline
\end{tabular}

Of the two patients operated on for a discharging sinus, one had no other physical abnormality and continues to be normal two years later. The other case, an infant aged 8 months, had bladder incontinence and is not improved three years later.

Both of the cases with bladder incontinence alone were adults aged 25 and 29 years. They indicate the potential danger underlying these lipomatous tumours. Neither had any physical defect but when aged 18 years both developed urinary symptoms and infection, the cause of which was not recognized; one had retention with overflow and the other dribbled urine continuously. Following laminectomy, the former patient regained some control of bladder function and the latter changed from total incontinence to retention with overflow; this was an improvement on her previous state and she was further relieved by bladder neck resection, but unfortunately there were already secondary changes in the renal tract and chronic infection so that later an ileal bladder had to be provided and total cystectomy performed.

Of the 15 patients with progressive neuropathy, one is worse as a direct result of the operation as has already been mentioned. Another, aged $2 \frac{1}{2}$ years, was incontinent and had weakness of the invertors of one foot together with a valgus deformity; four and a half years after laminectomy her clinical state was unchanged but at five years she had started to develop overaction of the muscles inverting the foot and had some degree of equinus. The ankle jerks have always been absent and the plantar responses continue to be flexor; this is probably the beginning of clinical deterioration so that her operation has failed in its purpose. Six cases show no change and the remaining seven show some improvement (Table II). In the long term, improvement is difficult to assess in children because of existing foot deformity which will continue to increase because the bones and joints are already abnormal and the subsequent normal muscle balance cannot correct it, but the rate of deformation is slowed down. In sensory loss, there may be detectable decrease or disappearance of previous areas of anaesthesia and analgesia, but where there has been trophic ulceration in the past, there may not be sufficient recovery of sensation in the toes to prevent recurrence of ulceration, although the speed of healing and the decreased frequency of ulceration is occasionally very evident and are indications of post-operative improvement.

The satisfactory outcome in our cases is manifested in these ways and in improvement of gait, reduction of spasticity, and disappearance of hip contracture. Recovery of previously absent or abnormal reflexes and diminution of the area of sensory loss occurred in three patients out of seven who had had detectable abnormality before laminectomy. In younger children such abnormalities are difficult if not impossible to assess. 


\section{DISCUSSION}

A lumbosacral lipoma may appear to be innocent but in 18 out of the 26 patients reported here it had a direct connexion with the spinal cord or cauda equina. It is evident, therefore, that any operation done to remove the tumour should include an exploration of the underlying spinal cord and cauda equina. Even if no direct connexion is traced there may well be a further abnormality which can be treated surgically as there has been in each of our cases.

We entirely agree with Dubowitz et al. (1965) that the operation should not be undertaken lightly; it can be difficult and there is always a risk of damaging nerve elements but, with reasonable care, the risk is slight provided that the surgeon is experienced in spinal cord surgery and especially if the excision of the lipoma and the deep exploration are done at the same operation. Our experience with patients whose lipomas were only superficially excised at an early age and who later developed neuropathy shows that secondary exploration is both difficult and dangerous; it should, however, be done since it may succeed in preventing subsequent deterioration, and one of our patients showed some improvement. Our one bad result occurred in this group.

The only account of a post-mortem examination we have found was Athol Johnson's case (1857) which had a lumbosacral lipoma adherent to the dura in the lower sacrum at which level he successfully removed it during life. The wound healed and the child was clinically improved, but six weeks after returning home he developed peritonitis and died. Examination at necropsy showed laminal defects in the lower sacrum and a normal coccyx; the external lipoma continued through the dura mater and extended cranially, pressing on the spinal cord in the sacral canal and involving the cauda equina whose roots were embedded in its substance. The report of this case clearly indicates that the conus medullaris was sited at or below Sv3 level and that it was subject to pressure. The tumour had been small at birth but had enlarged considerably at about 8 months of age and 'the child began to suffer from frequent twitchings or convulsive movements, affecting the right leg only, to such an extent as to make the parents anxious to have something done'. After the operation, which was carried out when the boy was 10 months old, the convulsive movements ceased and he went home a fortnight later. In the remaining six weeks of life he "was even able to stand, and was beginning to walk a little.' This case suggests that removal of the superficial lipoma alone can relieve symptoms by decompressing the area; however, three of our patients who had previously had the lipoma only removed in infancy came to us because of lower limb abnormalities which developed later, when they were 3,9 , and 10 years old.

Unfortunately, there is no means of determining whether there is or is not a deep connexion from the subcutaneous lipoma except by exploration. Myelography which demonstrates a low conus medullaris is an indication of abnormality and is therefore helpful. An attempt to correlate the clinical findings in our 26 cases with the abnormalities found at laminectomy gives no assistance; there is no correlation (see Appendix).

In this review we have made scant reference to the patients who were clinically normal apart from the presence of the subcutaneous lipoma; there were seven such cases. They presented because the parents wished to have the unsightly prominence removed and some also because their doctors wished to be advised. They were operated upon without a prolonged period of observation because preliminary myelography showed an abnormality in every case.

Because of the nature of the abnormality we have seen at laminectomy in the majority of our cases, the direct connexion between the subcutaneous lipoma and the intrathecal structures, it is difficult to believe that it can fail to affect the spinal cord and nerve roots at some time in the life of the individual and we consider that these tumours should be removed as a preventive measure. We are supported in taking this view by Brickner (1918), Bassett (1950), and Dubowitz et al. (1965), and are reinforced in our opinion by the situation of our two adult patients who developed bladder dysfunction at the age of 18 years.

This condition is not widely known although it is not rare and we know because of the later referral of patients to us that even when neurological deficit occurs the cause is often not recognized. We have other patients, later cases not included in this series, who have been treated symptomatically over long periods whose doctors had been completely unaware why their patients should be suffering in this way. Some of these patients had been submitted to several operations on the bladder or had had toes amputated one by one. It seems to us that at present, because the subject is so little known, we have the alternatives of recommending surgical removal of the lipoma and deep exploration within the theca in every case encountered or of explaining the nature of the abnormality to each individual patient as well as giving an account of the possible sequelae which might occur at any time in his life so that he recognizes the early symptoms if they should appear. The second alternative we regard as altogether unethical as being likely to distress the patient and cause him to become severely neurotic and anxious. There is no doubt that when the tumour is large, the case will 
have to be operated on for cosmetic reasons alone and exploration must be undertaken within the meninges to make sure that any deep connexion is removed.

If the principle of preventive operation is to be avoided, it is essential for the subject to be widely discussed so that clinicians likely to encounter these cases, particularly neurologists, genito-urinary surgeons, paediatricians, and orthopaedic surgeons, should recognize the early signs and make sure that the primary cause is removed promptly.

There has been little written on this particular topic and we ourselves were unaware of its significance until some time after we had become interested in spina bifida occulta. Searching the literature we came upon Bassett's paper (1950) and found that his views coincided with ours. He reported nine cases with similar findings at operation; his oldest patient was a woman aged 34 years. Our oldest patient (not in this series) is a woman whose first symptoms of incontinence occurred at the age of 42 , but she was 44 years old when the cause was finally recognized. The subsequent laminectomy fortunately succeeded and she recovered full bladder control. Brincker(1918) also reported cases of the same type, including that of a man aged 30 years who had developed trophic ulceration of the buttocks two years previously; this man recovered sensation as a result of the laminectomy performed so that the ulcers healed rapidly and they had not recurred during the following two years.

Bassett (1950) designates the condition 'lipoma of the cauda equina' as also do Dubowitz and his collaborators (1965). We ourselves have always preferred the term 'lumbosacral lipoma' (Lassman and James, 1963) because we have found a wider variety of intrathecal abnormality associated with the tumour of the back than the other writers. Dubowitz et al. (1965) seem to have found widespread lipomatous material in the cauda equina in every one of their 12 cases whereas this was not a prominent feature in any of ours. Only two of Bassett's nine cases appear to have had intrathecal lipomatous material. On balance, therefore, we suggest that the condition be called 'lumbosacral lipoma' because this brings into prominence the one feature common to all these cases and which permits easy diagnosis. Whether the specification should be lumbar or lumbosacral is an open question.

\section{SUMMARY}

In a series of 100 consecutive cases of spina bifida occulta submitted to laminectomy there were 26 of lumbosacral lipoma and these cases are surveyed. Four were adults and 22 were children.
The clinical syndrome and methods of investigation, including myelography, are described.

In 18 cases the subcutaneous lipoma was in continuity with the conus medullaris, with the cauda equina, or with the filum terminale. The remaining eight all had underlying abnormalities affecting the neural tissue and these were amenable to surgical alleviation. There is no correlation between the clinical state and the type of anomaly found at operation to give a guide in deciding whether surgery will benefit the patient or not.

Of 18 patients with physical abnormalities, one is worse as the result of operation, one shows evidence of deterioration five years later, nine show some improvement, and seven are unchanged.

It is stressed that in every case the lipoma should be excised and the spinal cord and cauda equina explored. It is better not to operate than to remove only the superficial tumour. However, because of the nature of the congenital abnormality and the risk of late onset of symptoms, it is wiser to operate in early infancy as a preventive of future neurological deficit.

Our grateful thanks are due to Dr. G. L. Gryspeerdt neuroradiologist, Dr. J. D. Whitby, anaesthetist, an Sister C. Palfreyman, ward sister, who have collaborated closely with us in this work, Dr. John N. Walton for hi® helpful advice in the preparation of this paper, and alsథ to our research secretary, Miss Sandra McVitie.

The operations were photographed by Mr. R. WO Ridley and Mrs. P. Bone, of the Department of Medicat Photography of the University of Newcastle upon Tyne

Our research in spina bifida occulta is supported by $y^{+}$. grants from the Medical Research Council and the Scientific and Research Committee of the Newcastle Regional Hospital Board.

\section{REFERENCES}

Bassett, R. C. (1950). The neurologic deficit associated with lipomas of the cauda equina. Ann. Surg., 131, 109-116.

Bentley, J. F. R., and Smith, J. R. (1960). Developmental posterior enteric remnants and spinal malformations. Arch. Dis. Childh., 35, 76-86.

Brickner, W. M. (1918). Spina bifida occulta. Amer. J. med. Sci., 155, 473-502.

Dubowitz, V., Lorber, J., and Zachary, R. B. (1965). Lipoma of the cauda equina. Arch. Dis. Childh., 40, 207-213.

Gryspeerdt, G. L. (1963). Myelographic assessment of occult forms of spinal dysraphism. Acta radiol. Diagn. (Stockh.), 1, 702-717.

Ingraham, F. D., and Lowrey, J. J. (1943). Spina bifida and cranium bifidum. III. Occult spinal disorders. New Engl. J. Med., 228 745-750.

— and Swan, H. (1943). Spina bifida and cranium bifidum. I. A survey of 546 cases. Ibid., 228, 559-563.

James, C. C. M., and Lassman, L. P. (1958). Diastematomyelia. Arch. Dis. Childh., 33, 536-539.

- (1960). Spinal dysraphism. An orthopaedic syndrome in children accompanying occult forms. Ibid., 35, 315-327.

- (1962a). Spinal dysraphism. The diagnosis and treatment of progressive lesions in spina bifida occulta. J. Bone Jt. Surg. 44B, 828-840.

,$--(1962 b)$. Spinal dysraphism. Spinal cord lesions associated with spina bifida occulta. Physiotherapy, 48, 154-157. 
(1964). Diastematomyelia. A critical survey of 24 cases submitted to laminectomy. Arch. Dis. Childh., 39, 125-130.

Johnson, A. (1857a). Fatty tumour from the sacrum of a child, connected with the spinal membranes. Trans. path. Soc. Lond., 8, 16-18.

(1857b). Fatty tumour connected with the interior of the spinal canal of the sacrum. Ibid., 8, 28-29.

Lassman, L. P., and James, C. C. M. (1963). Lumbosacral lipomata and lesions of the conus medullaris and cauda equina. Excerpta med. (Amst.), Int. Cong. Series, No. 60, pp. 139-141.

\section{APPENDIX}

ATTEMPTED CORRELATION OF CLINICAL FINDINGS AND ABNORMALITIES FOUND AT LAMINECTOMY

The full results are set out in Table I on page 176.

\section{TABLE}

CONNEXION BETWEEN LIPOMA AND INTRATHECAL STRUCTURES

Traced to spinal cord .............14

to filum terminale $\ldots \ldots \ldots \ldots \ldots$

to cauda equina $\ldots \ldots \ldots \ldots \ldots \ldots \ldots 1$

Not traced................. 8

Total ....................... 26

Taking the 14 cases which had a direct connexion to the spinal cord (conus medullaris or immediately adjacent to it) nine had progressive lower limb neuropathy, five had not.

Of the five cases without lower limb neuropathy, three children were clinically normal, two children had a discharging sinus and one of them was also incontinent.

Of the nine cases (including one adult) which had progressive lower limb neuropathy only two were affected bilaterally. One had moderate spasticity of both lower limbs and at operation the spinal cord was found to be kinked dorsally and adherent to the dura immediately cranial to the conus medullaris and without herniation from the vertebral canal. The other case had relapsing club feet considered to be clinically significant and was incontinent; she was too young to be accurately tested for sensation. The lipoma connected directly to the conus medullaris.

This leaves seven cases with unilateral lower limb neuropathy. In three there was actual paralysis of foot muscles (peronei or tibiales) whilst the others had only general muscular weakness of the affected limb. Some had detectable sensory loss, one of whom also had trophic ulceration. One was incontinent as well. The adult, aged 22 years, had symptoms developing over several years; in early childhood she had been normal. She had increasing weakness of the invertors of one foot, poor circulation, sensory loss, and finally trophic ulceration.

In 13 of these 14 cases the conus medullaris was situated at an abnormally low level varying from Lv3 down to Sv2. In the 14th case, by contrast, the conus
(1964). Spina bifida cystica and occulta; some aspects of spinal dysraphism. Paraplegia, 2, 96-99.

Lichtenstein, B. W. (1940). 'Spinal dysraphism.' Spina bifida and myelodysplasia. Arch. of Neurol. Psychiat. (Chic.), 44, 792-809.

Schlegel, K. F. (1964). Spina bifida occulta und Klauenhohlfuss. Ergebn. Chir. Ortho., 46, 268-320.

Whitby, J. D. (1961). Spinal dysraphism and the anaesthetist. Anaesthesia, 16, 432-434.

Williams, D. I., and Nixon, H. H. (1957). Agenesis of the sacrum. Surg. Gyne. Obstet., 105, 84-88. medullaris lay at probably normal level for her age (8 months) over the body of Lv2; she was incontinent and her lower limbs were normal. There was a discharging sinus on the lipoma but the sinus track was blocked just external to its attachment to the dura mater; she had never had meningitis and her operation was not difficult.

In three children of the 14 cases being discussed, the filum terminale was not identified and could possibly have been the core of the deep connexion; two were clinically normal and one was affected in one leg and was incontinent. In this context is it interesting to note that the two adults who developed bladder incompetence at the age of 18 years and had no lower limb abnormality, both had a direct continuation of the subcutaneous lipoma to the filum terminale, i.e., the filum terminale ended subcutaneously. The conus medullaris was at Lv5 level in one and at Sv1 in the other. The only other case with this finding at operation was a clinically normal child aged 5 whose conus medullaris lay at Lv3 level.

In this correlation, it is not possible to examine the size of the area of attachment to the spinal cord or conus medullaris. There might be a difference between the two types but we have insufficient information. In no case was the site of attachment very large, but of the two cases with the largest area of adherence, one had bilateral spasticity and was incontinent. The other, unilaterally affected, became incontinent as a result of the operation owing to the adhesions resulting from previous superficial excision of the lipoma which prevented exploration. In the latter case the full extent of the adherence was not seen at operation whilst the former case had the spinal cord kinked to be adherent dorsally over a length of about $1.5 \mathrm{~cm}$. to the dura within the vertebral canal (almost a meningomyelocoele).

Apart from the patients in whom the connexion from the lipoma was also the filum terminale, a condition which one might postulate as being potentially liable to produce bladder incompetence, there is no other evidence here to give any indication that a particular abnormality found at operation will be associated with any particular clinical syndrome, and there is no reason to be found why a patient should be incontinent without lower limb neuropathy any more than neuropathy should affect only one limb and not both. Nor is it possible to forecast that a patient at present normal will develop or will not develop a clinical abnormality later in life, but the nature of the surgical findings strongly suggest that a late developing clinical abnormality is likely. 